\title{
Peningkatan Kemampuan Menulis Karya Ilmiah Guru Melalui Pelatihan Penelitian Tindakan Kelas bagi Guru SD
}

\author{
Sri Lestari Handayani ${ }^{1}$, Diki Rukmana ${ }^{2}$ \\ ${ }^{1,2}$ Pendidikan Guru Sekolah Dasar, Fakultas Keguruan dan Ilmu Pendidikan, Universitas \\ Muhammadiyah Prof. DR. HAMKA \\ srilestarih@uhamka.ac.id
}

\begin{abstract}
ABSTRAK
Mitra kegiatan pengabdian masyarakat ini adalah guru-guru SD di Gugus Urip Sumoharjo. Masalah yang dialami oleh guru-guru SD meliputi (1) Kurangnya pemahaman guru mengenai pelaksanaan PTK, (2) Kurangnya pemahaman guru tentang penulisan proposal PTK, (3) Kurangnya pemahaman guru dalam melaporkan hasil PTK, dan (4) Kurangnya kepercayaan diri guru dalam melakukan PTK, dan (5) Kurangnya pengalaman guru dalam melakukan PTK. Tujuan dari pelatihan ini adalah untuk meningkatkan kemampuan guru dalam menyusun proposal, melakukan penelitian tindakan kelas dan melaporkannya. Kegiatan pelatihan dilaksanakan dalam tiga tahap yaitu : tahap persiapan, tahap pelaksanaan dan tahap pelaporan. Pelaksanaan pelatihan ini dapat dikatakan berhasil. Indikator yang menjadi tolak ukur keberhasilan pelaksanaan kegiatan pengabdian ini adalah tercapainya tujuan kegiatan yakni meningkatnya pemahaman guru mengenai PTK, meningkatnya motivasi dalam melaksanakan PTK dan guru memperoleh pengalaman langsung dalam menyusun proposal PTK.
\end{abstract}

Kata kunci: Penelitian Tindakan Kelas, Karya Tulis Ilmiah, Guru Sekolah Dasar

\section{ABSTRACT}

The partners of this community service activity are elementary school teachers in the Urip Sumoharjo Cluster. Problems experienced by elementary school teachers include (1) Lack of teacher understanding about the implementation of action research, (2) Lack of teacher understanding about writing action research proposals, (3) Lack of teacher understanding in reporting action research results, and (4) Lack of teacher confidence in conducting action research, and (5) Lack of teacher experience in conducting action research. The purpose of this training is to improve the teacher's ability to prepare proposals, conduct classroom action research and report on them. The training activities were carried out in three stages, namely: the preparatory stage, the implementation phase and the reporting stage. The training was successful. Indicators that serve as benchmarks for the successful implementation of these community service activities are the achievement of the objectives of the activity namely increasing teacher understanding of action research, increasing motivation in implementing action research and teachers gain hands-on experience in preparing action research proposals.

Keywords: Action Research, Scientific Paper, Elementary Teacher

\section{PENDAHULUAN}

Tujuan pendidikan nasional adalah mengembangkan potensi peserta didik agar menjadi manusia yang beriman dan bertakwa kepada tuhan Yang Maha Esa, berakhlak mulia, sehat, berilmu, cakap, kreatif, mandiri dan menjadi warga negara yang demokratis dan bertanggung jawab (UU No. 20 tahun 2003). Untuk mencapai tujuan tersebut, salah satu komponen pendidikan yang berperan aktif sebagai pelaksana pendidikan adalah pendidik atau guru.Untuk dapat melaksanakan sistem pendidikan nasional dan mewujudkan tujuan pendidikan nasional, seorang guru harus memiliki empat standar kompetensi meliputi: kompetensi pedagogik, kompetensi kepribadian, kompetensi sosial dan kompetensi profesional (UU No.14 Tahun 2015) Keempat kompetensi tersebut pada intinya ditujukan agar seorang guru dapat merencanakan pembelajaran, melaksanakan pembelajaran yang bermutu, menilai dan mengevaluasi hasil pembelajaran, serta melaksanakan perbaikan dan pengayaan (Permen PAN RB No. 16 
Tahun 2009)

Agar guru dapat terus menjaga kualitas pembelajaran di sekolah, maka guru harus terus melakukan kajian, menciptakan inovasi dan melakukan berbagai perubahan di dalam proses pembelajaran di kelas. Salah satu upaya yang dapat dilakukan guru adalah dengan melakukan Penelitian Tindakan Kelas (PTK). PTK dikatakan sebagai salah satu upaya meningkatkan kualitas pembelajaran karena didalam pelaksanaanya gagsan atau permasalahan yang dihadapi oleh guru diuji dan dikembangkan dalm bentuk tindakantindakan yang diarahkan pada proses pembahaaruan (Wiraatmadja, 2005). PTK sangat mendukung program peningkatan kualitas pembelajaran di sekolah yang muaranya adalah peningkatan kualitas pendidikan (Puslitjakdikbud, 2015: 2)

Pentingnya melakukan PTK bagi seorang guru tercermin dengan dijadikannya PTK sebagai salah satu syarat mendapat sertifikat profesi pada pelaksanan pendidikan sertifikasi guru dan juga dijadikan salah satu syarat perolehan angka penilaian bagi guru yang akan mengajukan kenaikan jabatan fungsional. Fakta yang ditemukan di lapangan bahwa sebagian besar guru masih memiliki antusiasme yang rendah terhadap pelaksanaan PTK. Hal tersebut disebabkan oleh keterbatasan kemampuan dan pengalaman guru dalam melakukan penelitian terutama PTK.

Masalah yang dialami oleh guru-guru SD meliputi (1) Kurangnya pemahaman guru mengenai pelaksanaan PTK, (2) Kurangnya pemahaman guru tentang penulisan proposal PTK, (3) Kurangnya pemahaman guru dalam melaporkan hasil PTK, (4) Kurangnya kepercayaan diri guru dalam melakukan PTK, dan (5) Kurangnya pengalaman guru dalam melakukan PTK.

Berdasarkan hal tersebut maka perlu dilakukan suatu kegiatan yang dapat membantu guru untuk dapat meningkatkan pemahaman dan keterampilan dalam melaksanakan PTK. Hal inilah yang menjadi dasar untuk dialakukan kegiatan Pengabdian pada Masyarakat berupa pelatihan menulis karya tulis ilmiah berupa Penelitian Tindakan Kelas (PTK).

Tujuan kegiatan pengabdian kepada masyarakat ini adalah untuk meningkatkan pemahaman, keterampilan, motivasi serta pengalaman guru SD dalam menyusun proposal, melaksanakan dan melaporkan hasil Penelitian Tindakan Kelas. Beberapa manfaat yang dapat diperoleh oleh guru dangan mengikuti kegiatan ini selain menjadi bekal wawasan untuk dapat meningkatkan kualitas pembelajaran didalam kelas, beberapa manfaat lainnya diantaranya adalah: sebagai upaya guru untuk membantu dalam persiapan memperoleh sertifikasi serta sebagai upaya persiapan bagai guru yang hendak mengajukan kenaikan jabatan fungsional.

Penelitian Tindakan didefinisikan sebagai studi sistematis dari upaya meningkatkan praktik pendidikan oleh kelompok partisipan dengan cara tindakan praktis mereka sendiri dan dengan cara refleksi mereka sendiri terhadap pengaruh tindakan tersebut (Hopkin dalam Emzir). Pada awalnya penelitian tindakan menjadi salah satu model penelitian yang dilakukan pada bidang pekerjaan tertentu dimana peneliti melakukan pekerjaannya, baik di bidang pendidikan, kesehatan maupun pengelolaan sumber daya manusia

Dalam konteks pendidikan, penelitian tindakan yang dilakukan oleh seorang guru biasa disebut sebagai Penelitian Tindakan Kelas (Action Reaserch) atau disingkat PTK. Dalam hal ini, kelas tidak terikat pada pengertian ruang kelas, tetapi dalam pengertian yang lebih spesifik, yaitu kelas adalah sekelompok siswa yang dalam waktu yang sama, menerima pelajaran yang sama dari guru yang sama juga (Suharsimi: 2005). PTK bertujuan untuk memperbaiki program pembelajaran di kelas dengan mengorganisasi pembelajaran secara sistematik untuk memperoleh hasil yang lebih baik (Mills dalam Creswell, 2011).

Tabel 1. Tinjuan tentang Penelitian Tindakan Kelas (PTK)

\begin{tabular}{llrl}
\hline No & Aspek PTK & & \multicolumn{2}{c}{ Penjelasan } \\
\hline 1 & Manfaat PTK & 1. & $\begin{array}{l}\text { Dapat dilakukan oleh hampir semua ahli di semua tipe sekolah, } \\
\text { (Fraenkel, 2012) }\end{array}$ \\
& & $\begin{array}{l}\text { semua level, guru kelas baik secara individu maupun berkelompok, } \\
\text { ataupun pimpinan sekolah. }\end{array}$ \\
& & 2. $\begin{array}{l}\text { Dapat memperbaiki praktik pendidikan; membantu praktisi } \\
\text { pendidikan (guru, pimpinan sekolah) dalam meningkatkan } \\
\text { kompetensi terhadap apa yang mereka lakukan. }\end{array}$ \\
\hline
\end{tabular}




\begin{tabular}{ll}
\hline No Aspek PTK & \multicolumn{1}{c}{ Penjelasan } \\
\hline 3. & $\begin{array}{l}\text { Memberi ruang kepada guru atau praktisi lain untuk mengadakan } \\
\text { penelitian mereka sendiri sehingga dapat mengembangkan cara-cara } \\
\text { yang lebih efektif untuk mempraktikkan keahlian-keahlian mereka } \\
\text { sendiri. }\end{array}$ \\
4. $\begin{array}{l}\text { Membantu guru mengidentifkasi masalah-masalah dan isu-isu secara } \\
\text { sistematis. }\end{array}$ & 5apat membangun sebuah komunitas yang berorientasi penelitian \\
& ilmiah di dalam sekolah itu sendiri
\end{tabular}

$2 \quad$ Karakteristik PTK

(Muslich, 2010)

1. Masalah PTK berawal dari guru: Masalah yang ditemukan guru di dalam kelas sebagai pelaku pembelajaran dapat menjadi topik utama dalam melakukan penelitian

2. Tujuan PTK adalah memperbaiki pembelajaran: Implikasi dari tujuan ini adalah guru tidak boleh mengorbankan proses pembelajaran karena sedang melakukan PTK.

3. PTK adalah penelitian yang bersifat kolaboratif: Seorang guru dapat berkolaborasi dengan dosen tenaga ahli ataupun teman sejawat dalam melaksanakan PTK, sehingga dapat saling memberikan masukan tentang prosedur pelaksanaan PTK dengan benar

4. PTK adalah jenis penelitian yang memunculkan adanya tindakan tertentu untuk memperbaiki proses belajar mengajar di kelas: Tindakan-tindakan ini dapat berupa penggunaan metode pembelajaran tertentu, penerapan strategi pembelajaran, pemakaian media/sumber belajar, jenis pendekatan tertentu, atau hal-hal inovatif lainnya.

5. PTK dapat menjembatani kesenjangan antara teori dan praktik pendidikan: Hal ini terjadi karena dengan melakukan PTK berarti seorang guru dapat membuktikan apakah sebuah teori pembelajaran dapat diterapkan secara efektif atau tidak di kelasnya, sehingga ia dapat memperoleh balikan yang bagus untuk perbaikan proses pembelajaran berikutnya.

\section{$3 \quad$ Prinsip-prinsip} PTK

(Arikunto, 2006)
1. Kegiatan nyata dalam situasi rutin

Penelitian yang dilakukan peneliti tidak boleh mengubah suasana rutin, penelitian harus dalam situasi yang wajar, sehingga hasil penelitian dapat dipertanggungjawabkan.

2. Adanya kesadaran diri untuk memperbaiki kerja

Kegiatan penelitian tindakan kelas dilakukan bukan karena keterpaksaan, akan tetapi harus berdasarkan keinginan guru, guru menyadari adanya kekurangan pada dirinya atau pada kinerja yang dilakukannya dan guru ingin melakukan perbaikan.

3. SWOT sebagai dasar berpijak

Penelitian tindakan dimulai dengan melakukan analisis SWOT, yang terdiri atas unsur-unsur Strength (kekuatan), Weaknesses (kelemahan), Opportunity (kesempatan) dan Threat (ancaman). Empat hal tersebut dilihat dari sudut guru yang melaksanakan maupun siswa yang dikenai tindakan. Dengan berpijak pada hal-hal tersebut penelitian tindakan dapat dilaksanakan hanya bila ada kesejalanan antara kondisi yang ada pada guru dan juga siswa.

4. Upaya Empiris dan Sistemik

Dengan telah dilakukannya analisis SWOT dalam PTK, berarti guru sudah mengikuti prinsip empiris (terkait dengan pengalaman) dan sistemik, berpijak pada unsur-unsur yang terkait dengan keseluruhan sistem yang terkait dengan objek yang sedang digarap.

5. Ikuti Prinsip SMART dalam Perencanaan Kata SMART yang artinya cerdas mempunyai makna dalam proses 


\begin{tabular}{ll}
\hline No Aspek PTK & \multicolumn{1}{c}{ Penjelasan } \\
& perencanaan kegiatan penelitian tindakan yaitu : S-specific, khusus, \\
& tidak terlalu umum, M-Managable, dapat dikelola, dilaksanakan, A- \\
& Acceptable, dapat diterima lingkungan, atau Achievable, dapat \\
& dicapai, dijangkau, R-Realistic, operasional, tidak di luar jangkauan \\
& dan. T-Time-bond, diikat oleh waktu, terencana.
\end{tabular}

Secara umum terdapat 4 tahapan yang biasa dilalui pada PTK yaitu (1) perencanaan, (2) pelaksanaan, (3) pengamatan dan (4) refleksi. Pada tahap perencanaan, peneliti menentukan fokus permasalahan yang akan diteliti, kemudian membuat perangkat pembelajaran serta instrumen pengamatan untuk menjaring data dan fakta yang terjadi pada waktu proses tindakan berlangsung. Pada tahap pelaksanaan, strategi dan rencana pembelajaran yang telah disiapkan pada tahap perencanaan, dilaksanakan. Pada tahap ini guru harus ingat dan mentaati apa yang dirumuskan dalam rencana pembelajaran, berlaku wajar dan tidak dibuat-buat. Pada tahap pengamatan dilakukan pengamatan dan pencatatan semua hal yang diperlukan dan yang terjadi selama pelaksanaan tindakan berlangsung. Pengumpulan data dilakukan dengan bantuan format observasi yang telah dipersiapkan, termasuk juga pengamatan secara cermat pelaksanaan tindakan dari waktu ke waktu serta dampaknya terhadap proses dan hasil belajar siswa. Tahap refleksi dimaksudkan untuk mengkaji secara menyeluruh tindakan yang telah dilakukan, berdasarkan data yang telah terkumpul kemudian dilakukan evaluasi guna menyempurnakan tindakan berikutnya

\section{METODE KEGIATAN}

Pelaksanaan kegiatan pelatihan PTK bertempat di gedung SD Muhammadiyah 11 Bidaracina Jakarta Timur. Jumlah peserta sebanyak 30 orang dan merupakan perwakilan dari 10 sekolah yang berada pada kelompok Gugus Urip Sumoharjo. Bentuk kegiatan pelatihan ini berupa seminar dan penugasan. Seminar diberikan untuk memberi penyegaran dan penguatan kepada peserta untuk mengingat dan mengenal kembali Penelitian Tindakan Kelas. Urutan materi yang diberikan meliputi (1) Pengertian, prinsip-prinsip, karakteristik dan pelaksanaan PTK, (2) Penyusunan proposal PTK, dan (3) Penyusunan laporan PTK. Setelah kegiatan seminar, peserta diberikan penugasan untuk mencoba menyusun proposal PTK yang terwakili oleh masing-masing sekolah.

Kegiatan Pengabdian pada masyarakat ini dilaksanakan dalam tiga tahap yaitu : tahap persiapan, tahap pelaksanaan dan tahap pelaporan. Pelaksanaan masing-masing tahapan diuraikan yang tampak pada Gambar 1.

\begin{tabular}{|c|c|c|}
\hline Tahap Persiapan & & Tahap \\
\hline $\begin{array}{l}\text {-Melakukan pengamatan } \\
\text { lapangan } \\
\text {-Konfirmasi lapangan } \\
\text { - Menyusun tim pelaksana } \\
\text { - Menyusun proposal } \\
\text { kegiatan }\end{array}$ & $\begin{array}{l}\text { - Mengecek pemahaman } \\
\text { awal guru mengenai PTK } \\
\text { - Memberikan materi } \\
\text { mengenai prinsip umum } \\
\text { PTK } \\
\text {-Memberikan materi } \\
\text { mengenai penyusunan } \\
\text { proposal dan laporan PTK } \\
\text { - Mengadakan workshop } \\
\text { penyusunan proposal } \\
\text { PTK } \\
\text {-Mengecek kembali } \\
\text { pemahaman guru } \\
\text { mengenai PTK }\end{array}$ & $\begin{array}{l}\text { - Memberikan fasilitas } \\
\text { pendampingan bagi guru } \\
\text { yang akan } \\
\text { menyelenggrakan PTK } \\
\text { - Mengadakan evaluasi } \\
\text { program } \\
\text { - Menyusun laporan } \\
\text { kegiatan }\end{array}$ \\
\hline
\end{tabular}

Gambar 1. Tahapan Kegiatan Pelatihan Penelitian Tindakan Kelas 


\section{HASIL \& PEMBAHASAN}

Berdasarkan pelaksanaan kegiatan pelatihan PTK yang bertempat di gedung SD Muhammadiyah 11 Bidaracina Jakarta Timur, jumlah peserta pelatihan yang hadir adalah sebanyak 30 orang guru SD yang berasal dari 10 sekolah yang berada pada Gugus Urip

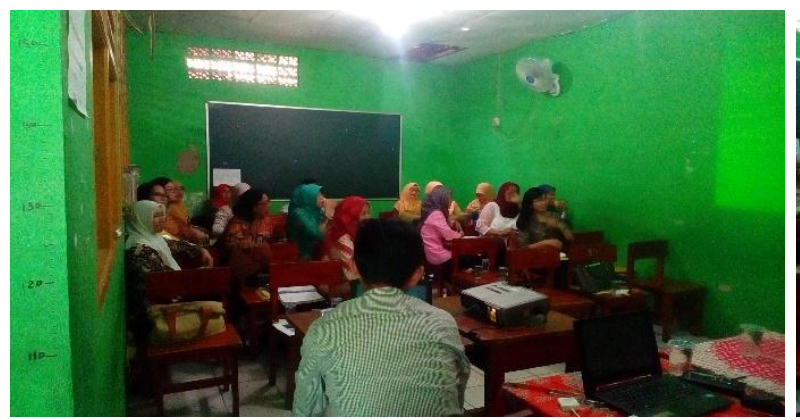

Gambar 2. Proses Kegiatan Pelatihan PTK

Setelah kegiatan pelatihan selesai, disepakati bahwa bagi peserta pelatihan yang segera melaksanakan kegitan PTK diberikan fasilitas pendampingan mulai dari penulisan proposal, pelaksanaan penelitian sampai pada pelaporan hasil penelitian.

Tujuan utama kegiatan pengabdian kepada masyarakat ini adalah untuk meningkatkan pemahaman, motivasi, serta pengalaman guru SD dalam menyusun proposal, melaksanakan dan melaporkan hasil Penelitian Tindakan Kelas. Berdasarkan hasil pelaksanaan kegiatan pelatihan yang telah dilaksanakan maka terdapat temuan yaitu sebelum mengikuti kegiatan pelatihan, sebagian besar guru memiliki pemahaman mengenai PTK yang kurang. Hal tersebut dapat terlihat dari proses diskusi yang kurang hidup. Sebagain besar guru terlihat pasif dan tidak memberikan respon jawab ketika pemateri bertanya hal-hal seputar PTK.saran Setelah mengikuti kegiatan pelatihan, terlihat bahwa pemahaman guru mengenai PTK lebih meinungkat. Hal tersebut dapat terlihat dari proses diskusi yang lebih hidup dan banyaknya peserta yang merespon dengan baik ketika pemateri mengajukan pertanyaan seputar PTK.

Motivasi guru dalam mengikuti pelatihan PTK ini cukup tinggi, hal ini terlihat dari banyaknya peserta yang mengikuti kegiatan ini dan jumlahnya tetap bertahan hingga pelaksanaan pelatihan selesai. Selain itu, motivasi guru juga terlihat dari banyaknya pertanyaan yang diajukan pada sesi diskusi dan banyaknya ide/gagasan yang disampaikan pada
Sumoharjo Kecamatan Jatinegara Jakarta Timur. Pelaksanaan pelatihan dilakukan selama 1 hari. Pelatihan diberikan dengan urutan materi sebagai berikut (1) Pengertian, prinsip-prinsip, karakteristik dan pelaksanaan PTK, (2) Penyusunan proposal, dan (3) Penyusunan laporan PTK. Proses paparan materi dapat dilihat pada Gambar 2 berikut.

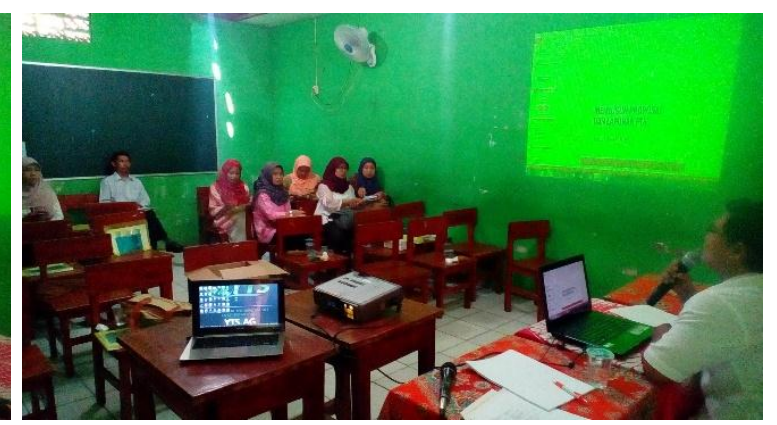

saat pelaksanaan workshop penulisan proposal PTK.

Pada sesi kegiatan workshop penulisan proposal PTK, guru cukup antusias untuk mengungkapkan ide dan gagasan yang mereka miliki, mulai dari identifikasi masalah, membuat kalimat judul, menyusun outline latar belakang maasalah, merumuskan masalah, merumuskan tujuan, menyusun outline kajian pusataka sampai pada pemaparan metode penelitian. Pada sesi ini seluruh guru terlibat aktif dalam penyusunan draft proposal dengan harapan guru dapat memperoleh pengalamn sendiri dalam menyusun proposal PTK.

\section{KESIMPULAN \& SARAN}

Berdasarkan hasil dan pembahasan, maka dapat disimpulkan bahwa secara garis besar pelaksanaan pelatihan ini dapat dikatakan berhasil. Indikator yang menjadi tolak ukur keberhasilan pelaksanaan kegiatan pengabdian ini adalah tercapainya tujuan kegiatan yakni meningkatnya pemahaman guru mengenai PTK, meningkatnya motivasi dalam melaksanakan PTK dan guru memperoleh pengalaman langsung dalam menyusun proposal PTK. Adapun indikator yang menunjukan keberhasilan dalam memberikan pengalaman melaksanakan PTK dan melaporkan hasil PTK masih belum dapat terukut. Hal tersebut karena belum ada peserta yang secara resmi mengajukan permohonan pendampingan dalam melaksanakan dan melaporkan hasil PTK. Pada kegiatan pengabdian selanjutnya dapat dikuatkan dengan memberikan pendampingan secara 
khusus kepada guru-guru SD untuk melakukan penelitian tindakan kelas hingga mampu membuat laporan PTK dengan baik dan benar.

\section{DAFTAR PUSTAKA}

Arikunto, S. (2006). Penelitian Tindakan Kelas. Jakarta: Bumi Aksara.

Emzir, (2008). Metodologi Penelitian Pendidikan: Kuantitatif dan Kualitatif. Jakarta: PT. RajaGrafindo Persada.

Fraenkel, J .R.,et al. (2012). How to Design and Evaluate Research in Education (8th). New York: The McGraw-Hill Companies, Inc.

Kementerian Pendidikan dan Kebudayaan Badan Penelitian dan Pengembangan Pusat Penelitian Kebijakan. (2015). Panduan Pelaksanaan Program Penelitian Tindakan Kelas Tingkat Satuan Pendidikan Tahun 2016.

Muslich, M. (2010). Melaksanakan PTK (Penelitian Tindakan Kelas) itu Mudah. Jakarta: Bumi Aksara

Peraturan Pemerintah Nomor 23 Tahun 2013 Tentang Standar Nasional Pendidikan juncto Peraturan Pemerintah Nomor 19 Tahun 2005 Tentang Standar Nasional Pendidikan

Peraturan Menteri PAN Nomor 16 Tahun 2009 Tentang Jabatan Fungsional Guru dan Angka Kreditnya

Undang-Undang Nomor 20 Tahun 2003 tentang Sistem Pendidikan Nasional.

Undang-Undang Nomor 4 Tahun 2005 tentang Guru dan Dosen.

Wiraatmadja, R. (2014). Metode Penemilitan Tindakan Kelas. Bandung : PT. Remaja Rosdakarya. 